\title{
Mapping of the gene for cleidocranial dysplasia in the historical Cape Town (Arnold) kindred and evidence for locus homogeneity
}

MRC Research Unit for Medical Genetics, Department of Human Genetics, University of Cape Town, Medical School, Observatory 7925, South Africa

R S Ramesar

J Greenberg

R Martin

R Goliath

$S$ Bardien

P Beighton

Department of Cell Biology, Harvard Medical School, Boston, USA $S$ Mundlos

Correspondence to: Dr Ramesar.

Received 23 October 1995 Revised version accepted for publication 9 January 1996

Rajkumar S Ramesar, Jacquie Greenberg, Rebecca Martin, Rene Goliath, Soraya Bardien, Stefan Mundlos, Peter Beighton

\begin{abstract}
Cleidocranial dysplasia (CCD) is an autosomal dominant disorder, features of which include a patent anterior fontanelle, a bulging calvarium, hypoplasia or aplasia of the clavicles, a wide pubic symphysis, dental anomalies, vertebral malformation, and short stature. The Cape Town kindred which is under our genetic management was originally described more than four decades ago and now consists of more than 1000 people. Following reports of rearrangements on chromosomes 6 and 8 in people with CCD, we have carried out linkage analyses between highly information microsatellite dinucleotide repeat markers in the rearranged regions and the disorder in a branch of this South African CCD kindred, consisting of 38 subjects, 18 of whom are affected. Maximum lod scores (at $\theta=0 \cdot 00$ ) of 7.14 (for marker D6S459), 4.32 (TCTE), 4.99 (D6S452), 5.97 (D6S269), and 3.95 (D6S465) confirm linkage of the disorder to the short arm of chromosome 6. Our data indicate that the CCD gene is located within a minimal region of approximately $10 \mathrm{cM}$ flanked by the marker D6S451 distally and D6S466 proximally. This information is vital towards isolating and characterising the gene for CCD, and is being used to construct a physical map of 6p21.1-6p21.3. More importantly, mapping of the locus in the South African kindred of mixed ancestry, in which the "founder" of the disorder was of Chinese origin, suggests that a single locus is responsible for classic CCD.
\end{abstract}

(f Med Genet 1996;33:511-514)

Key words: cleidocranial dysplasia; linkage; skeletal; chromosome 6 .

Cleidocranial dysplasia (CCD) is an autosomal dominant disorder characterised by persistent patency of the anterior fontanelle of the skull and variable hypoplasia of the clavicles. The major clinical features are a bulky forehead and undue mobility of the shoulder girdle. Affected subjects have variable dental anomalies; although they may have a generally slight stature, they are not dwarfed and enjoy good general health.

The Cape Town family investigated in this study was originally described by Jackson, ${ }^{1}$ and to date is the only kindred with CCD described on the African continent. The disorder occurs in many descendants of an affected Chinese immigrant who arrived in South Africa in 1896, embraced the Mohammedan religion, and had seven wives. In his assessment of the kindred, Jackson $^{1}$ was able to trace a large number of the descendants of the original progenitor, of whom 70 had the craniofacial features of CCD, locally referred to by the family as the "Arnold head".

Brueton $e t \mathrm{al}^{2}$ described three subjects with CCD in whom rearrangements of chromosome $8 q 22$ were apparent cytogenetically. Nienhaus et $a l^{3}$ subsequently documented a pericentromeric inversion of chromosome 6 in a patient with classic CCD. Mundlos et $a l^{4}$ investigated markers on $8 \mathrm{q}$ and in the pericentromeric region on chromosome 6 and showed linkage between the $6 p$ markers and the disorder in two large CCD families. The disorder was mapped to a region of about $23 \mathrm{cM}$. In one kindred, a microdeletion encompassing the marker D6S459 was shown to segregate with the disorder. Feldman et $a \bar{l}$ subsequently analysed five families with CCD and showed evidence for localisation of the defective gene within a $19 \mathrm{cM}$ interval on the short arm of chromosome 6 . The region described by these workers was adjacent to but did not overlap the microdeleted region of Mundlos et al. ${ }^{4}$ More recently, Gelb et al refined the CCD interval, through work on two families, to a region of $6 \mathrm{cM}$, based on previously published marker distances. ${ }^{7}$

We investigated the disorder in a sizeable branch of the South African kindred ${ }^{1}$ in order to ascertain the extent, if any, of locus heterogeneity. We undertook molecular investigations in the affected multigeneration Cape Town family using markers in regions suggested by previously published rearrangements (for $8 \mathrm{q} 22^{2}$ ) and linkage data (for $6 \mathrm{p}^{4-6}$ ). Our findings are presented and discussed in this paper.

Subjects and methods

THE AFFECTED FAMILY

The affected family are of a Chinese, San, Xhoi-Xhoi, European, Javanese, West African, and Madagascan admixture. In 1953, Jackson documented 253 affected persons in this kindred and traced the arrival of the defective gene to a mariner who settled in the Cape in 1896 . This person, who was of Chinese stock, married seven wives of mixed ancestry and founded a 


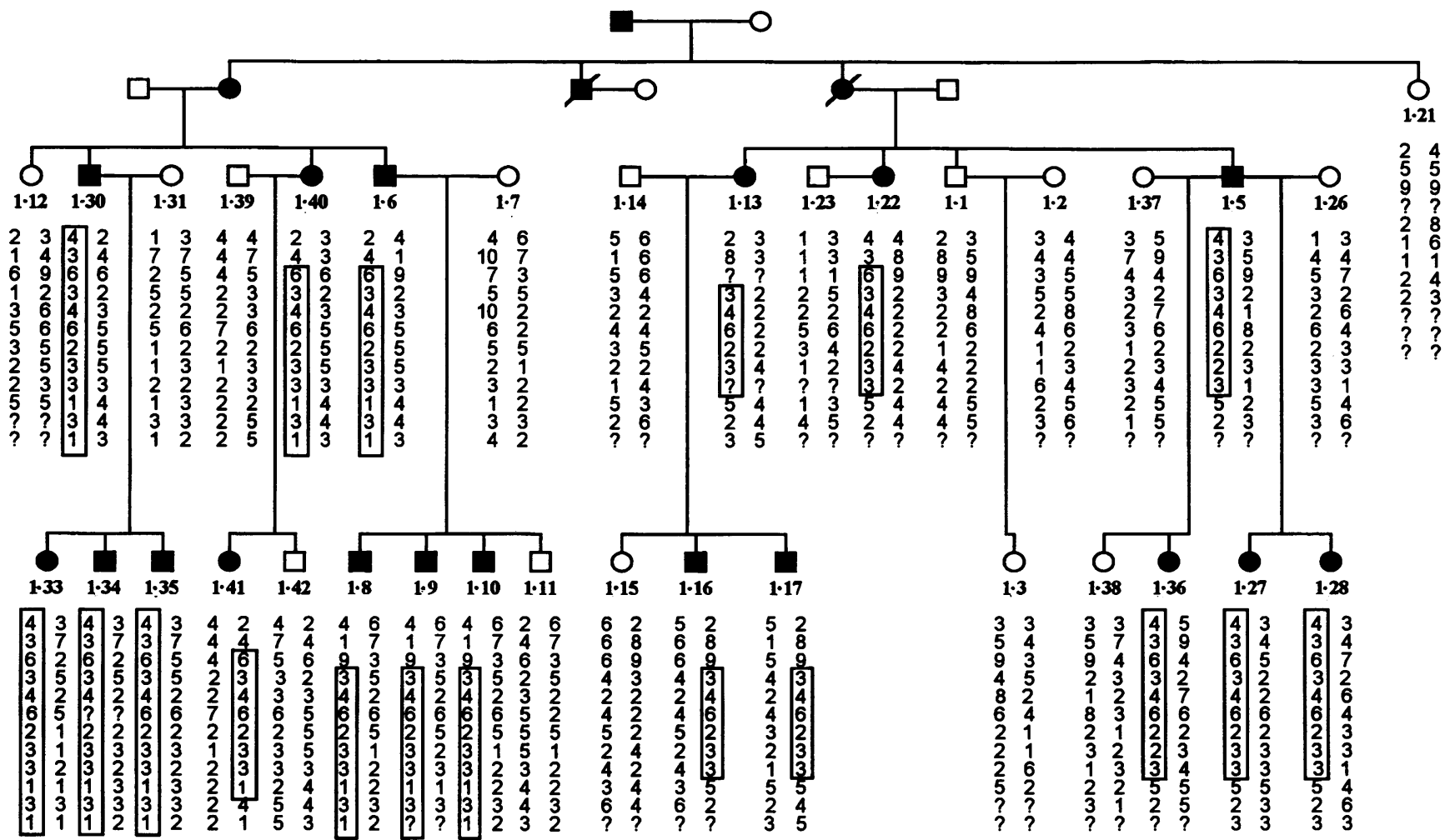

Figure 1 The pedigree of the CCD kindred with marker genotypes indicated. The order of the markers as indicated in the genotypings is: D6S439, D6S282, D6S426, D6S451, D6S459, TCTE1, D6S452, D6S269, D6S465, D6S466, D6S295, FTHP1.

dynasty with CCD. During the past two decades we have continued the clinical and genealogical studies instituted by Jackson and more than 100 affected family members have been ascertained and examined. We estimate that more than 1000 descendants of the first progenitor now have the disorder.

The present investigation was undertaken in a branch of the family in which 38 persons in three generations were studied. The pedigree of this section of the kindred is shown in fig 1. Diagnostic confirmation was obtained by means of skull and chest (clavicular) radiographs, and $30 \mathrm{ml}$ blood specimens were collected by venepuncture from each affected person and unaffected first degree relatives.

\section{DNA TYPING}

Microsatellite markers from the published Weissenbach Linkage set ${ }^{7}$ were purchased from Research Genetics (Huntsville, AL, USA). Twelve loci were analysed: D6S439, D6S426, D6S451， D6S282， D6S459, D6S452, D6S269, D6S465, D6S466, D6S295, ${ }^{7}$ TCTE $1,{ }^{8}$ and FTHP $1 .{ }^{9}$ PCR reactions were carried out in a total volume of $10 \mu \mathrm{l}$ and contained $200 \mathrm{ng}$ DNA, $10 \mathrm{pmol}$ of each primer, $250 \mu \mathrm{mol} / 1$ of dNTPs, $1 \mu \mathrm{Ci}$ of $\alpha-$ dCTP, $1.5 \mathrm{mmol} / 1 \quad \mathrm{MgCl}_{2}, 50 \mathrm{mmol} / 1 \mathrm{KCl}$, $10 \mathrm{mmol} / \mathrm{l}$ Tris-HCl (pH 8.3). Following the addition of 1 unit of Taq polymerase, amplification of each sample was performed in a thermal cycler (Omnigene National Labnet, Woodbridge, NJ, USA). The samples were denatured at $94^{\circ} \mathrm{C}$ for four minutes, followed by 30 cycles of $94^{\circ} \mathrm{C}$ for 40 seconds, $55^{\circ} \mathrm{C}$ for 50 seconds, and $72^{\circ} \mathrm{C}$ for 50 seconds. A final elongation step of $72^{\circ} \mathrm{C}$ for seven minutes was used to complete the reaction.

The amplified products were mixed with an equal volume of formamide loading buffer, denatured at $94^{\circ} \mathrm{C}$ for three minutes, and re-

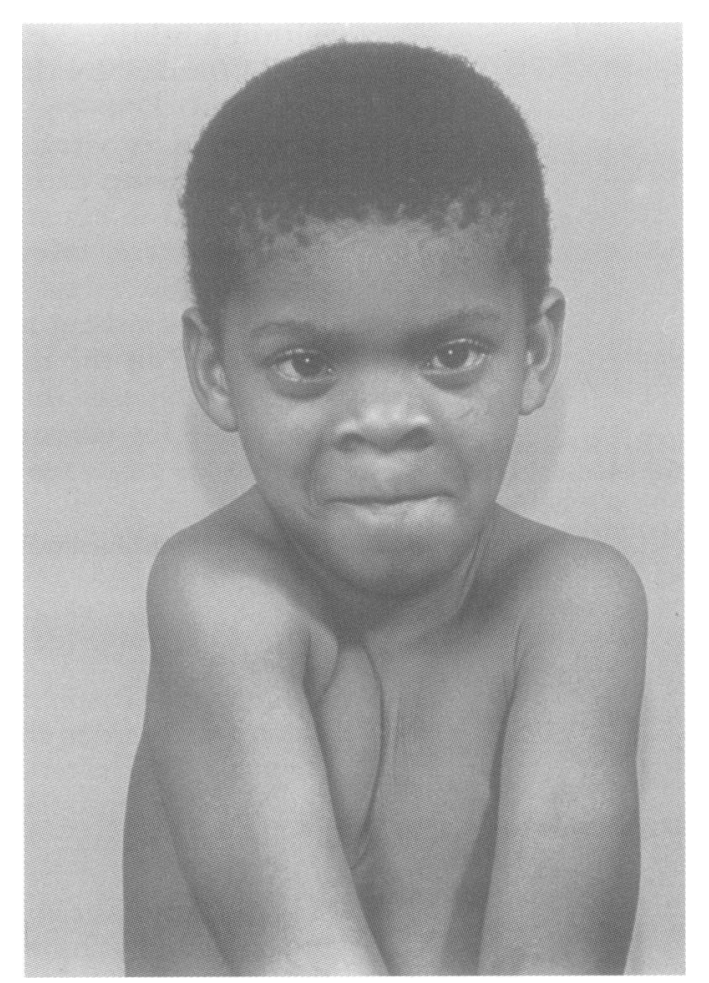

Figure 2 An affected child (aged 11 years) with the characteristic bulky forehead and pointed face ("Arnold head"). The excessive mobility of the shoulders is apparent. 


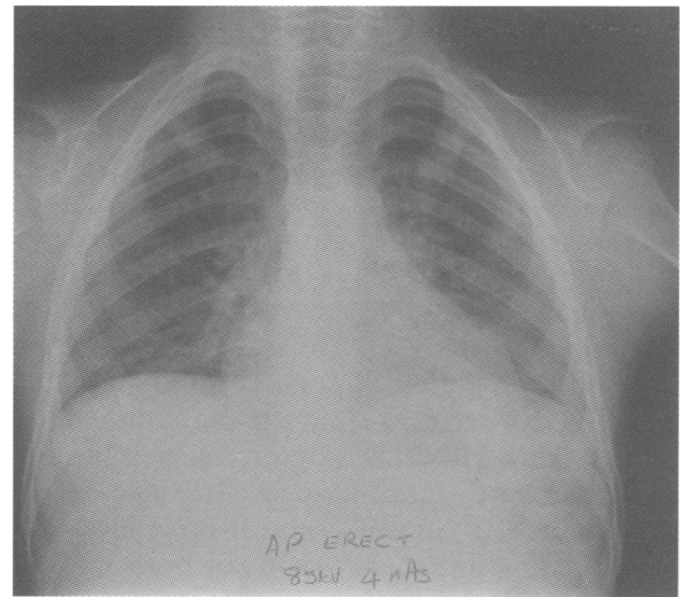

Figure 3 Anteroposterior radiograph of the chest of an adolescent, showing hypoplasia of the clavicles.

solved on a $6 \%$ denaturing polyacrylamide sequencing gel containing 32\% urea. Gels were dried and exposed to Agfa Curix film overnight at $-80^{\circ} \mathrm{C}$.

\section{LINKAGE ANALYSIS}

Pairwise linkage analyses were conducted using LINKAGE version $5 \cdot 03 .{ }^{10}$ We assumed autosomal dominant inheritance of a rare gene (frequency 0.00001 ) with full penetrance (= 1). For each marker, the allele frequencies were presumed to be equal.

\section{Results}

\section{PATIENTS}

The affected persons exhibited variable combinations of the following clinical signs: moderate short stature, brachycephaly, midfacial hypoplasia (shown in fig 2 , and typically being recognised as the "Arnold head"1), clavicular hypoplasia (fig 3) or aplasia (leading to abnormal facility in apposing the shoulders (fig 2), narrow thorax, short ribs, hypoplastic pubic bones, wide pubic symphysis, delayed eruption of permanent teeth, brachydactyly, persistently open skull sutures with bulging calvaria and wormian bones, short middle phalanx of the fifth finger, multiple cone shaped epiphyses, and slightly retarded skeletal maturation throughout childhood. The diagnosis in our patients was confirmed by radiological examination of the skull and clavicles. Although the clavicles were variably hypoplastic, com- plete absence of the clavicles was unusual. Supernumerary teeth were a significant feature of the disorder in this kindred.

\section{LINKAGE ANALYSIS}

We excluded markers on chromosome $8 \mathrm{q} 22$ based on maximum lod scores below -2 at $\theta=0.05$. Two point lod scores for markers on chromosome 6 are summarised in the table. Maximum lod scores at $\theta=0.00$ were obtained for markers D6S459 (7.14), TCTE (4.32), D6S452 (4.99), D6S269 (5.97), and D6S465 (3.95). Markers flanking the region and which produced maximum lod scores at $\theta=0.05$ are D6S451 distally and D6S466 proximally. The order of these markers is as they occur on the Genethon map. ${ }^{7}$ Our results support the localisation of marker D6S451 proximal to the marker D6S282, as suggested by Gelb et al. ${ }^{6}$

\section{Discussion}

The population frequency of CCD in Cape Town is probably the highest in the world. The situation can be attributed to the founder effect together with the innocuous nature of the condition, against which there is little or no negative biological pressure. In our experience, the majority of affected members of the South African kindred do not suffer any ill effects of the disorder, apart from the dental problems accompanying the abnormal teeth. Mentality is normal and stature, although slight, is within the normal range.

The mapping of CCD on chromosome 6 is important for providing evidence for a common gene locus (homogeneity) for familial CCD, and for the isolation and characterisation of the gene underlying the disorder. The characterisation of the biological roles of genes underlying disorders such as CCD will lead to an understanding of the complex process of bone morphogenesis.

Our evidence of linkage in one of the largest CCD kindreds ever described confirms the localisation of the disorder on $6 p$ and supports the reports of other workers. ${ }^{4-6}$ Our investigation provides strong evidence for the CCD gene lying centromeric to marker D6S451 and telomeric to D6S466. The region of approximately $10 \mathrm{cM}$ encompasses marker D6S459, which is within the microdeletion described in a CCD family by Mundlos et al. ${ }^{4}$ Our data, with those of the previous workers, ${ }^{46}$ suggest

Results of linkage analysis between chromosome 6 markers and CCD in the Cape Town family

\begin{tabular}{|c|c|c|c|c|c|c|c|c|c|c|c|c|}
\hline \multirow[t]{2}{*}{ Marker } & \multicolumn{11}{|c|}{ Recombination fraction $(\theta)$} & \multirow{2}{*}{$\begin{array}{l}\text { No of } \\
\text { alleles }\end{array}$} \\
\hline & 0.00 & 0.05 & $0 \cdot 10$ & 0.15 & $0 \cdot 20$ & 0.25 & $0 \cdot 30$ & 0.35 & 0.40 & 0.45 & 0.50 & \\
\hline $\begin{array}{l}\text { D6S439 } \\
\text { D6S282 } \\
\text { D6S426 } \\
\text { D6S451 } \\
\text { D6S459 } \\
\text { TCTE1 } \\
\text { D6S452 } \\
\text { D6S269 } \\
\text { D6S465 } \\
\text { D6S466 } \\
\text { D6S295 } \\
\text { FTHP1 }\end{array}$ & $\begin{array}{r}-22.52 \\
-16.26 \\
-\quad 7.42 \\
-12.07 \\
7.14 \\
4.32 \\
4.99 \\
5.97 \\
3.95 \\
0.69 \\
-10.64 \\
-\quad 1.84\end{array}$ & $\begin{array}{l}0.90 \\
1.12 \\
1.35 \\
2.23 \\
6.56 \\
4.01 \\
4.51 \\
5.43 \\
3.61 \\
3.87 \\
1.30 \\
1.48\end{array}$ & $\begin{array}{l}1 \cdot 61 \\
1 \cdot 81 \\
1 \cdot 60 \\
2 \cdot 22 \\
5 \cdot 95 \\
3 \cdot 68 \\
4 \cdot 13 \\
4 \cdot 87 \\
3 \cdot 27 \\
3 \cdot 70 \\
1 \cdot 69 \\
1 \cdot 46\end{array}$ & $\begin{array}{l}1.79 \\
1.98 \\
1.59 \\
2.06 \\
5.32 \\
3.32 \\
3.67 \\
4.29 \\
2.89 \\
3.37 \\
1.68 \\
1.32\end{array}$ & $\begin{array}{l}1.74 \\
1.91 \\
1.45 \\
1.80 \\
4.64 \\
2.94 \\
3.19 \\
3.67 \\
2.50 \\
2.96 \\
1.50 \\
1 \cdot 10\end{array}$ & $\begin{array}{l}0.15 \\
1.70 \\
1.23 \\
1.50 \\
3.93 \\
2.52 \\
2 \cdot 68 \\
3.04 \\
2.09 \\
2.50 \\
1.20 \\
0.88\end{array}$ & $\begin{array}{l}1.26 \\
1.39 \\
0.97 \\
1 \cdot 15 \\
3 \cdot 18 \\
2.07 \\
2 \cdot 15 \\
2.37 \\
1.65 \\
1.99 \\
0.83 \\
0.62\end{array}$ & $\begin{array}{l}0.91 \\
1.01 \\
0.68 \\
0.78 \\
2.39 \\
1.60 \\
1.59 \\
1.70 \\
1.21 \\
1.43 \\
0.43 \\
0.35\end{array}$ & $\begin{array}{l}0.52 \\
0.60 \\
0 \cdot 40 \\
0.41 \\
1.55 \\
1 \cdot 10 \\
1.00 \\
0.99 \\
0.75 \\
0 \cdot 85 \\
0 \cdot 11 \\
0.01\end{array}$ & $\begin{array}{r}0 \cdot 19 \\
0.23 \\
0 \cdot 16 \\
0 \cdot 11 \\
0 \cdot 69 \\
0.56 \\
0.43 \\
0.38 \\
0.31 \\
0.30 \\
-0.05 \\
-0.05\end{array}$ & $\begin{array}{l}0.00 \\
0.00 \\
0.00 \\
0.00 \\
0.00 \\
0.00 \\
0.00 \\
0.00 \\
0.00 \\
0.00 \\
0.00 \\
0.00\end{array}$ & $\begin{array}{r}6 \\
10 \\
9 \\
5 \\
10 \\
8 \\
5 \\
7 \\
6 \\
5 \\
8 \\
5\end{array}$ \\
\hline
\end{tabular}


that the CCD gene lies within a region of between 4 and $5 \mathrm{cM}$ between D6S451 and D6S465. It is likely that with an extension of the number of subjects in our study we would be able to narrow the region further. However, although members of this kindred live in and around Cape Town, it is difficult to recruit core families for investigations, probably because the condition is not regarded as serious.

Although Feldman et aP mapped their CCD families to $6 p$, their results indicate that the gene for the disorder in the kindreds investigated lies telomeric to markers D6S282 and D6S271, which are a significant distance away from the distal crossover in the South African kindred, at D6S451. It is possible that the discrepant results reflect genetic heterogeneity for CCD. This could be because of the possible regional clustering of genes for bone morphogenetic components. However, it is possible, as suggested by Gelb et $a l,{ }^{6}$ that there may be an error in map assignments of the markers.

Interestingly, the reports of linkage to $6 \mathrm{p}$ are in diverse population groups; genealogical evidence indicates that the disorder in the Cape Town kindred described here originated in China (although it is possible that the disorder occurred sporadically in the founder). Mundlos et $a l^{4}$ reported on two kindreds of European origin (with no nationality indicated), in which the disorder was localised to $6 \mathrm{p}$, and Feldman et $a \bar{P}$ described five French CCD kindreds. Gelb et at who investigated the disorder in two families, one French-Canadian and one St Lucian, localised the CCD gene to a region of $6 \mathrm{cM}$.

The next phase of our effort and those of other investigators internationally is to identify the disease causing gene. Our findings, and recruitment of additional members of the vast CCD kindred for linkage analysis, will almost certainly diminish considerably the critical region for a gene search. With the present evidence for linkage of familial CCD to chromosome $6 \mathrm{p}$, questions of genetic heterogeneity may be answered with the testing for linkage of additional CCD families, using markers from this region. This approach will also be useful for determining whether other disorders which share some of the features of $\mathrm{CCD}$, such as aplastic clavicles, are the result of defects in the same gene, or in related genes.

We are further refining the region of the abnormal gene using more people from the affected kindred. We are also in the process of obtaining YACs from this region in order to test our markers and candidate genes, for example, the bone morphogenetic proteins (BMP5 and BMP6 $6^{11-13}$ ) for colocalisation. It would be reasonable to determine whether any of the candidate genes reside within the minimal region for CCD on chromosome $6 \mathrm{p}$, while at the same time testing these genes for defects by established mutation detection techniques, such as single stranded conformation polymorphism analysis or PCR sequencing of their exons or both.

Our work was supported by grants from the Medical Research Council of South Africa, the Harry Crossley Foundation, the Mauerberger Foundation, and the University of Cape Town Staff Research Fund. We are grateful to Sr Lecia Bartmann for her assistance in recruiting members of the CCD kindred and Sue Schultz and Jon Moller for technical assistance.

1 Jackson WPU. Osteo-dental dysplasia (cleido-craWPU. Osteo-dental dysplasia (cleido-cranialysostosis).

2 Brueton LA, Reeve A, Ellis R, Husband P, Thompson EM Kingston HM. Apparent cleidocranial dysplasia associated with abnormalities of $8 \mathrm{q} 22$ in three individuals. $A m \mathcal{F} M e d$ Genet 1992;43:612-18

3 Nienhaus H, Mau U, Zang KD, Henn W. Pericentric inversion of chromosome 6 in a patient with cleidocrania dysplasia. Am 7 Med Genet 1993;46:630-1.

4 Mundlos S, Mulliken JB, Abramson DL, Warman ML, Knoll JHM, Olsen BR. Genetic mapping and evidence for a microdeletion in cleidocranial dysplasia. Hum Mol Genet 1995;4:71-5.

5 Feldman GJ, Robin NH, Brueton LA, et al. A gene for cleidocranial dysplasia maps to the short arm of chrocleidocranial dysplasia maps to the short arm

6 Gelb BD, Cooper E, Shevell M, Desnick RJ. Genetic mapping of cleidocranial dysplasia (CCD) locus on chroping of cleidocranial dysplasia (CCD) locus on chromosome band 6p21 to in

Genet 1995;58:200-5.
7 Gyapay G, Morisette J, Vignal A, et al. The 1993-94 Genethon human genetic linkage map. Nature Genet 1994 7:246-92.

8 Kwiatkowski TJ Jr, Beaudet AL, Trask BJ, Zoghbi HY Linkage mapping and fluorescence in situ hybridisation of TCTE 1 in human chromosome $6 \mathrm{p}$ : analysis of dinucleotide polymorphisms on native gels. Genomics 1991 10:921-6.

9 Mauvieux V, Dugast I, El Kahloun A, et al. A HindIII RFLP at the FTHP locus on chromosome 6. Nucleic Acids Res 1991;19:6969.

10 Lathrop GM, Lalouel JM. Easy calculations of lod scores and genetic risks on small computers. Am $\mathcal{f}$ Hum Genet and genetic ris

11 Hahn GV, Cohen RB, Wozney JM, et al. A bone morphogenetic protein subfamily: chromosomal localisation of human genes for BMP5, BMP6, BMP7. Genomics 1992, 14:759-62

12 Urist MR. Bone: formation by autoinduction. Science 1965 150:893-9.

13 Kingsley DM, Bland AE, Grubber JM, et al. The mouse short ear skeletal morphogenesis locus is associated with defects in a bone morphogenetic member of the TGFbeta superfamily. Cell 1992;71:399-410. 